\section{Summary}

The results of treatment of 260 cases of pituitary adenoma by a combined surgical and radiotherapeutic technique have been reviewed: all operations were performed through the transfrontal route, and all but 19 patients surviving for more than six weeks received irradiation subsequently.

The overall mortality rate at operation and within the subsequent six weeks was $10 \%$. Among the 45 patients (18\% of the total) with large or extensive tumours the operative mortality rate was $33 \%$, while among the remainder it was just under $5 \%$.

The most frequent cause of death at or within six weeks of operation was trauma of or haemorrhage into the brain, while cerebral degeneration was the commonest cause of later deaths. Pituitary insufficiency alone caused only five out of the total of 88 deaths.

Symptoms of a recurrent tumour were recognized in $7.5 \%$ of survivors. Most occurred within five years of operation, but occasionally the interval was much longer. Second operations, whether or not performed for recurrence, obtained indifferent results.

Vision was improved by treatment in a little over one-half of the patients, and was unchanged in one-quarter. Deterioration occurred in about $15 \%$. Headache was usually relieved by operation, but lesions of the first and eighth cranial nerves were more common after treatment, owing to surgery and radiotherapy respectively.
This investigation was supported by a grant to one of us (S. G. E.) from the British Empire Cancer Campaign and forms part of a thesis presented by S. G. E. for the degree of M.D. of Cambridge University.

\section{REFERENCES}

Bakay, L. (1950). 7. Neurosurg., 7, 240.

Colby, M. Y., jun., and Kearns, T. P. (1962). Proc. Mayo Clin., 37, 15. Cushing, H. (1912). The Pituitary Body and its Disorders, p. 341 Philadelphia and London.

Elkington, S. G., Buckell, H. M. B., and Jenkins, J. S. (1967). Acta endocr. $(\mathrm{Kbh}$.$) . In press.$

Gurdjian, E. S., Webster, J. E., Latimer, F. R., Klein, S. P., and Lofstrom, J. E. (1955). ' . Amer. med. Ass., 158, 23.

Heinismann, J. I., and Czerny, L. I. (1926). Strahlentherapie, 24, 331.

Henderson, W. R. (1939). Brit. F. Surg., 26, 811.

Horrax, G., Hare, H. F., Poppen, J. L., Hurxthal, L. M., and Younghusband, O. Z. (1952). F. clin. Endocr., 12, 631.

Smedal, M. I. Trump, J. G., Granke, R. C., and Wright, K. A (1955). New Engl. F. Med., 252, 524.

Horsley, V. (1906a). Brit. med. F., 1, 323.

- (1906b). Ibid., 2, 411.

Jefferson, G. (1940). Proc. roy. Soc. Med.., 33, 433.

McKissock, W. (1952). In S. Cade's Malignant Disease and its Treatment by Radium, 2 nd ed., vol. 4, pp. 478-486. London.

Mogensen, E. F. (1957). Acta endocr. (Kbh.) 24, 135.

Nurnberger, J. I., and Korey, S. R. (1953). Pituitary Chromophobe Adenomas, p. 282. New York.

Poppen, J. L. (1963). Bull. N.Y. Acad. Med., 39, 21.

Ray, B. S., and Patterson, R. H., jun. (1962). F. Neurosurg., 19, 1.

Svien, H. J., Love, J. G., Kennedy, W. C., Colby, M. Y., jun., and Kearns, T. P. (1965). Ibid., 22, 47.

Troen, P., and Rynearson, E. H. (1956). F. clin. Endocr., 16, 747

\title{
Driving after Temporal Lobectomy for Epilepsy*
}

\author{
MURRAY A. FALCONER, $\dagger$ M.CH., F.R.C.S., F.R.A.C.S.; DAVID C. TAYLOR, $\ddagger$ M.B., B.S., D.P.M.
}

The subject of epilepsy and driving licences was discussed in September 1965 at an International Symposium held in Vienna (Social Studies in Epilepsy, 1966), and again in 1966 at a combined meeting of the British Branch of the International League Against Epilepsy and the British Epilepsy Association (British Medical fournal, 1966). It seems clear that the application of the existing law in this country to those patients whose epilepsy is controlled is unsatisfactory, and we therefore propose to describe some findings gained during follow-up studies of patients whose epilepsy has been controlled by anterior temporal lobectomy, since they highlight the difficult nature of the problem.

The legal position of the epileptic who wishes to drive in this country seems at first sight to be clear enough. In completing the application form (D.L.I.R.-Revised-1965) he must answer the following question: "Do you suffer from either of the following diseases or disabilities ? . . . (1) Epilepsy ; (2) Sudden attacks of disabling giddiness or faintness." The penalty for knowingly making a false statement may be a fine not exceeding $£ 100$ or imprisonment for a term not exceeding four months, or both.

As Turner (1966) pointed out, difficulties arise from the interpretation of words "suffering from epilepsy," and also from the fact that driving licences in this country are not issued by a central Government authority but by local

* Read at a combined meeting of the British Branch of the Internationa League Against Epilepsy and the British Epilepsy Association, 10 May 1966.

Director, GuY's-Maudsley Neurosurgical Unit, London S.E.5

$\neq$ Research Assistant, Guy's-Maudsley Neurosurgical Unit, London S.E.5 authorities, who interpret these words variably. The ideas of laymen also vary, and we have found that quite often patients who have become fit-free after operation decide for themselves that they are no longer "suffering from epilepsy," and apply for and obtain a driving licence in the ordinary way without seeking medical or legal opinion. The licensing authorities have from time to time been given advice on the subject. Thus some years ago a committee of the Royal College of Physicians of London recommended that an applicant should have been fit-free for five years, for the last two of which he should have been off medication. In 1961 the Ministry of Transport sent a memorandum stating, inter alia: "The Department has received advice that epilepsy should be regarded as a continuing liability to recurrent epileptic attacks. It follows that a person who has in the past had one or more attacks of convulsions, or of disturbance of consciousness, in circumstances which are unlikely to recur, need not necessarily be regarded as suffering from epilepsy. ... In any case of doubt the licensing authority will no doubt consult the local county council or county borough medical officer of health. ..." There is also provision for a dissatisfied applicant having his case heard at a magistrate's court, a course of action with its inherent publicity which few individuals care to face.

\section{Present Position}

During the past 14 years about 200 patients with intractable temporal-lobe epilepsy have been operated on in the Guy'sMaudsley Neurosurgical Unit. Detailed studies of the operative 
results and of the underlying pathological processes in the first 100 patients have already been given (Falconer and Serafetinides, 1963 ; Falconer, Serafetinides, and Corsellis, 1964). The incidence of success as regards the relief of seizures (fit-free or almost so) in the first 100 patients appears to be $53 \%$, while in the second 100 patients it appears to be about $60 \%$. Since their operation we have maintained close contact with most of our patients, and in a recent study of the social adjustments of 100 consecutive patients (Cases 50 to 150 in our series) we have inquired into the question of driving licences and of road accidents while driving. This information we have regarded as privileged, since it has been given to us in confidence. Consequently, the case histories cited will not be identifiable by the system usually employed in our communications.

The follow-up period in these cases ranged from 3 to 10 years, and 13 patients $(13 \%)$ admitted to driving a car. A further 26 patients were in our opinion in a position to apply for a licence, but either did not wish to or said they did not know they could. It is readily possible that a few of these 26 , and indeed some of those with continuing seizures, were driving but withheld this information from us. This incidence of $13 \%$ of known drivers in a postoperative epileptic population compares with an incidence of about $30 \%$ in the population at large. Together with these 13 patients, however, we would like to cite two others from the remaining 100 , because of the special problems we encountered. This brings our group under discussion up to 15 patients, all but one to the best of our knowledge relieved of epilepsy. All are supposed to be off medication, but we know that a few of them still take anticonvulsant drugs, usually intermittently, and then generally when they know they are going to face a period of stress. We also know that some of them still have psychiatric disturbances.

Often we have been asked by patients after operation how they should proceed when applying for a driving licence. Our advice has consistently been that they should wait for two to three years after operation, and that if time then showed that they were seizure-free, and particularly if they were off drugs, we would give a letter to the licensing authority supporting their application. Yet only one (Case 1) of the 15 patients we are citing has asked for such a certificate when applying in this country.

\section{Case 1}

A 23-year-old man engaged in road construction work had had a mild head injury, with dazedness but without loss of consciousness, at the age of 20 . Six months later he began to have fits of varying degrees of severity, ranging from brief "absences" to major convulsive (grand mal) attacks. Most of these attacks started with a variety of auras, including an epigastric sensation, a sense of unreality, and sometimes also a " snatch of song." In the psychomotor attacks, which were occurring two or three times weekly, he would suddenly appear dazed and then fidget with his hands, while simultaneously making smacking movements of his lips. Seizures of this type would last from 30 seconds to 2 minutes, and postictally he had a transient dysphasia. They could not be controlled by drugs. C.N.S. examination between seizures was negative. The electroencephalogram (E.E.G.) showed a left inferior frontal (? or anterior temporal) slow-wave focus with spike discharges phasing at the left sphenoidal electrode. The I.Q. was above average. Skull $x$-ray films and air encephalograms were normal.

A $5-\mathrm{cm}$. anterior temporal lobectomy was performed under local analgesia with electrocorticographic control, and the resected specimen was found to contain a small lesion about $1 \mathrm{~cm}$. in diameter in the anterior part of the fusiform gyrus. Th:s lesion was originally reported by our group as a meningioma (Fig. 1, Meyer, Falconer, and Beck, 1954), but later was redescribed as a glial hamartoma (Cavanagh, 1958), which remains our current opinion. Postoperatively he became free of fits, and showed no deficits other than a minimal right upper homonymous hemianopia. He was kept on anticonvulsant drugs for one year. Two years postoperatively he told one of us that unless his driving licence could be renewed he would have to give up his job in the road-construction firm. A certificate was given him stating that to the best of our knowledge he had been fit-free since operation, that he had been off drugs for a year, that the resected specimen contained a lesion, and that his E.E.G. was now normal.

His licence was then renewed in one of the home counties, but the eminent neurologist who had referred him to us upbraided us on the grounds that we had not complied with the recommendation of the Royal College of Physicians, stating a minimum of five years' freedom from epilepsy, including two years off drugs. To have followed this recommendation in his case would have been punitive, for he would certainly have lost his job. He has now been seizure-free for 12 years, has not had a serious accident, and has become a director of his firm.

\section{Obtaining Licences}

The remaining 14 drivers have all obtained a current driving licence without reference to us or to their family doctor. They have done this either by renewing their old licences without mentioning their past medical history or, if young, by presenting themselves for a driving test in the ordinary way without mentioning their past medical history, except for one person who applied for a licence in California. When asked by us how they answered the question in the application form whether they "suffered from epilepsy," most of them replied that because of the operation they considered this no longer applied to themselves.

The motives that impelled these patients to obtain driving licences, and to drive, vary widely. Some did so because it was socially expected of them, others because it was necessary for their jobs, and yet others to prove their virility or to demonstrate their good health. Some of our patients have various associated psychiatric disturbances. This adds to further problems over driving, because the current application form for driving does ask questions about mental illnesses but phrases them in such a manner that grossly disturbed persons are excluded, as well as mental defectives and idiots, who would not understand the legal phraseology anyway. Those who do understand would regard this particular question as not applicable to themselves.

These patients are driving, and have either renewed their licences or gained a new licence to drive in all sorts of capacities, as the following four additional case histories show.

Case 2.-A man in his thirties, with an I.Q. of 108, gave a five-year history of epileptic attacks which began with a variety of auras, including epigastric and olfactory sensations, déjà vu, and enhanced perception. These occurred many times a week, and in some of them he had continued to drive in an automatic way. He had minimal left-sided pyramidal motor signs, and the E.E.G. showed slow-wave activity in the right fronto-temporal region. A $6-\mathrm{cm}$. right anterior temporal lobectomy revealed a cholesteatoma (inclusion dermoid) involving the uncus and amygdala. Eleven days postoperatively his E.E.G. was within normal limits. $\mathrm{He}$ had a mild transient diplopia from a fourth cranial-nerve paresis, and a slight defect in the left upper quadrantic field. Six months after operation he asked us about resuming his driving, but we told him to wait for two years. Thereafter at the yearly follow-up sessions we heard nothing further from him about driving, though we knew him to be a motor-car salesman, until five years postoperatively, when he gleefully showed us a cup he had recently won in a national driving rally. When then questioned by us about when he had resumed driving he told us it was within two months of operation.

Case 3.-A middle-aged man with a nine-year history of frequent psychomotor epileptic attacks had been a bus driver for the three years prior to his first recorded attack. On account of this attack he had to change his employment, and he started up a greengrocery business with his family. Apparently this business prospered and he acquired two shops, and regularly drove his own van to market. After operation, in spite of our warnings, and unknown to us, he resumed driving his van. A rather paranoid and egocentric man with great energy, he also established a driving- 
school about four years aiter operation, and gained the reputation of being a stern disciplinarian but one whose pupils seemed to be successful in passing their driving tests. He himself is not yet a certificated driving instructor, but as six years have passed since he started his school he will probably become automatically certificated if and when legislation is introduced to register all driving instructors. So far as we are aware, both from him and his family, he has been fit-free since operation. He has not disclosed his medical history to the licensing authorities, but from hearsay we have every reason to believe that he is a competent and forceful driver. The resected temporal lobe contained a glial hamartoma.

Case 4.-A 21-year-old girl with a five-year history of fits, similarly relieved by operation, passed her driving test 20 months after operation without declaring her medical history. She also applied unsuccessfully to several London teaching hospitals for entry as a student nurse, but the matron of one of these hospitals to whom we had furnished a medical certificate helped her admission to the nursing school of a provincial hospital. In due course she completed her training, married, and had a son. We understand she has now driven about 10,000 miles $(16,000 \mathrm{~km}$.) without an accident. She is fit-free and her resected temporal lobe shows mesial temporal sclerosis. Her aggressive immature personality has become normal.

Case 5.-A self-employed business man aged 36 had had febrile convulsions in infancy, but his habitual seizures did not begin until he was 23. They were mostly of psychomotor type, with an epigastric aura followed by postictal dysphasia, and their frequency ranged from two a week to several a day. Shortly before operation, after two seizures a few hours apart, he had a florid religiose psychotic episode lasting a week. The E.E.G. showed a left temporal lobe focus, and a left anterior temporal lobectomy disclosed mesial temporal sclerosis. He resumed driving three months postoperatively, and has continued for 10 years without accident or overt seizures, though occasionally he has transient epigastric sensations.

\section{Accidents}

To our knowledge only 3 out of 15 patients have had accidents while driving, only one of which has been serious, and it is difficult for us to tell whether or not epilepsy played a part in these events. Their stories briefly are as follows:

Case 6.-A youth who at times has a particularly bad temper, and whom we suspect still has seizures, was involved in a car accident while driving in a foreign country two years after operation; we understand that no serious injuries ensued, though the car was damaged. We do not know the details, but police action was not taken.

Case 7.-A young girl with paranoid schizophrenia, which she usually successfully hides from strangers, started driving four and a half years after her operation. One evening, on the way to a dance, she wandered across the road, struck a bollard, and damaged the underneath of her car. Her passenger was a policeman, who remonstrated with her for driving when the steering mechanisms were awry. An insurance company paid the full cost of repairs, presumably as they did not know her past medical history. Fortunately she has been reluctant to drive since.

Case 8.-A young man, who eight years after his operation was riding a motor-cycle, was involved in a collision which injured him so seriously that he was in hospital for a year. The police prosecuted the other driver, but we often wonder what their reaction would have been had they known about the cerebral operation, and that the injured person had obtained his licence without mentioning his past history.

\section{A Question of Duty}

Our own position in relation to these cases has often been a difficult one. Most of the information we have obtained about the driving habits of our patients has been gained in confidence, and we have respected that confidence. Had we not done so the information would have been withheld from us-indeed, several of the 15 patients we are citing did not confess that they were driving until some years after operation, and one of them even said that he started driving within two months of operation. It may well be that even more of our patients than we think are surreptitiously driving. A few patients who have not been operated on, including members of our own profession, but who know that we shall respect their confidence, and have therefore sought our advice on treatment, are still driving.

Yet we know that in addition to our duty to our patients we also have a duty to the community. Only twice have we exercised this in a positive way.

Case 9.-A youth aged 17 at the time of operation, with a history of epilepsy from the age of 2 years and an aggressive paranoid psychopathic personality, was observed by the local police to be driving postoperatively. His licence was twice rescinded, and on the second occasion our help was sought. We wrote that we did not think he was fit to drive, and when his licence was withdrawn on the second occasion he was promptly told that it was because of our certificate. This led to very difficult relations between us and him, and we have not seen him in recent years. By hearsay, however, we suspect that he is driving again.

Case 10.-This man we thought was a menace as a driver because of persistent epilepsy and his personality. We quietly wrote to the licensing authority recommending that when his licence came up for renewal (which was shortly) he should be asked to produce a medical certificate. He did not obtain one.

In some other cases where we have thought that driving would be dangerous we have remonstrated with the patients, and pointed out that if they had an accident and their history was disclosed they would be liable to police prosecution, and the insurance company would not pay the costs of damage to their cars or to themselves. We understand that by tacit agreement insurance companies in this situation usually settle any third-party injuries but refuse to accept the other liabilities. An instance of where we dissuaded a patient from driving is afforded by the following case history.

Case 11.-An engaging man in his thirties started to drive within three years of operation. He had no manifest seizures but still got occasional auras. He had a marked postoperative homonymous hemianopia and had been dichromatic from birth. We learnt that he had driven, apparently without accident, several thousands of miles without a licence. We think our entreaties have persuaded him to cease driving.

\section{Discussion}

This, then, is a survey of personal experiences of drivers after their temporal lobectomy for intractable epilepsy, and of driving licences. It demonstrates that frequently patients are prepared to go outside the current law. At the Vienna meeting last year (Social Studies in Epilepsy, 1966) the position of the epileptic driver was discussed by speakers from many different countries. Most countries have laws preventing persons with recurrent seizures from driving, but many also recognize that in certain circumstances seizures can be controlled by drugs or sometimes by operation, and that then under certain safeguards patients can be allowed to drive. Differences arise in the length of time which elapses after treatment has rendered the patient fit-free; furthermore, while some countries allow patients to drive while they are still on medication, others insist that they should be off drugs or should forswear alcohol. Some countries also demand a normal E.E.G., a criterion which all epileptologists know is often of uncertain value. Thus an active epileptic may on occasion have a normal E.E.G., while yet again electroencephalographic abnormalities may persist but the patient be clinically free of seizures. Again, the quality of electroencephalographic records varies greatly in different parts of the country.

From the Vienna symposium it would appear that comparatively few accidents arise directly from epilepsy. Speakers from Scandinavia (Lund, 1966) felt that epileptic attacks behind the wheel were responsible in their countries for from 0.03 to $0.1 \%$ of traffic accidents reported to the police, and that most of these accidents were harmless. Evidently in Norway and in Sweden, 
epilepsy is notifiable and has to be compulsorily reported by the doctor to the health authorities, but that in these two countries, as in Denmark, an epileptic can be allowed a licence if he has been seizure-free for two to three years, even if he is still on medication. Holland is another country with similar liberal views (Lorentz de Haas, 1966). German speakers recorded that the Federal German Bureau of Statistics reported that only a very small proportion $(0.21 \%)$ of all drivers who had been involved in traffic accidents were physically handicapped or suffered from health disabilities, and that convulsive disorders made up only a small fraction of their figures.

The most interesting figures came from the United States, where registration is a state and not a federal responsibility (Klöve and Forster, 1966). In Wisconsin in 1949 legislation was introduced by which patients who had been free of seizures for two years were explicitly allowed to drive after a favourable appeal to a special medical advisory board. The number of licensed epileptics driving rose between 1960 and 1965 from 888 to 1,722 , approximately double. In 1960 a survey showed that only three accidents due to a seizure had been recorded during the preceding 11 years-the period the law had been in operation-and that 74 of the then 888 licensed epileptics had been involved in an accident. This represents an accident rate of $8.3 \%$, with $0.33 \%$ due to seizures. The overall accident rate for Wisconsin for 1960 (accidents involving personal injuries or at least 50 dollars in property damage) was $47 \%$ of all drivers. It is therefore apparent that the accident rate for licensed epileptic drivers was much lower than the general average. This does not imply that the "epileptic" in Wisconsin is a better driver than the average, but that licensed epileptics are a screened and safer group. We understand that similar experiences and trends have been observed in California.

In all countries where epilepsy is notifiable there is a tendency for epilepsy to be driven underground, and this tendency becomes greater the more restrictive the legislation. To highlight some of the problems involved we have therefore given our own experience in a particular group of epileptics. The difficulty for any legislature is to work out a set of safeguards which will protect the community and at the same time enable epileptics whose seizures are controlled, whether by medication or operation or by a combination of factors, not to be penalized if they really do become fit-free. A five-year period of freedom from epilepsy can in certain circumstances be a punitive measure and a two-year or three-year period more equitable. Furthermore, it may be reasonable for patients who have undergone an apparently successful operation to continue taking small doses of medication, as many of them after long years of seizures are loath to take risks with their newly found freedom. A more rational method of screening erstwhile epileptics who wish to drive than is at present followed in this country seems desirable.

We suggest that all persons suffering from or having suffered from epilepsy should have their applications scrutinized in camera by a committee or board appointed by the licensing authority, and that on this board should sit at least one physician experienced in neurological diseases. The applicant could refer such medical certificates or other reports as he thinks fit, but the board itself would take into consideration evidence other than medical-for example, history of aggressive outbursts furnished by the police. The board need not state its reasons for deferring or refusing any application. In general, however, any person who had suffered from epilepsy could apply for a licence two or more years after he had become fit-free, even though he might still be on small prophylactic doses of anticonvulsants. Any aggrieved person refused a licence under the above system could then appeal to an appropriate court, when of course the details of his application would become public.

\section{Summary}

A survey of 100 consecutive patients with drug-resistant temporal-lobe epilepsy submitted to an anterior temporal lobectomy 3 to 10 years earlier has revealed that 13 patients are now driving motor vehicles. All these 13 patients are seizurefree, and in the authors' opinion a further 26 patients could reasonably apply for a driving licence if they were so disposed.

To this 13 cases are added two other cases, for they collectively illustrate some of the problems encountered when erstwhile epileptic patients start driving. Only one patient, to the authors' knowledge, supplied a medical certificate to the licensing authorities when applying for renewal of his licence in this country; the remaining patients, except for one in California, did not disclose their past medical history to the driving authorities. Yet as a group these particular patients seem competent drivers, and indeed some have excelled.

The above information has been gained in confidence, and it is possible that an even higher proportion of 'patients drive. The difficulties that confront the medical attendant when patients whom he knows to be a menace insist on driving are also touched upon.

The legal position in this and other countries is reviewed, and suggestions are made for a more liberal attitude towards the problem if drivers who have recovered from epilepsy are not to be penalized. Suitable safeguards for both driver and the community are discussed.

One of us (D. C. T.) wishes to acknowledge a grant kindly given jointly by the Bethlem Royal and Maudsley Hospitals and by Guy's Hospital.

\section{REFERENCES}

Brit. med. F., 1966, 1, 1536.

Cavanagh, J. B. (1958). Brain, 81, 389.

Falconer, M. A., and Serafetinides, E. A. (1963). F. Neurol. Neurosurg. Psychiat., 26, 154.

- and Corsellis, J. A. N. (1964). Arch. Neurol., 10, 233.

Klöve, H., and Forster, F. M. (1966). Social Studies in Epilepsy, No. 4, p. 16.

Lorentz de Haas, A. M. (1966). Ibid., p. 23.

Lund, M. (1966). Ibid., p. 7. Meyer, A., Falconer, M. A., and Beck, E. (195.4). F. Neurol. Neurosurg.
Psychiat., 17, 276.

Social Studies in Epilepsy, 1966, No. 4. "Epilepsy and Driving

Turner, A. (1966). Social Studies in Epilepsy, No. 4, p. 4. 